

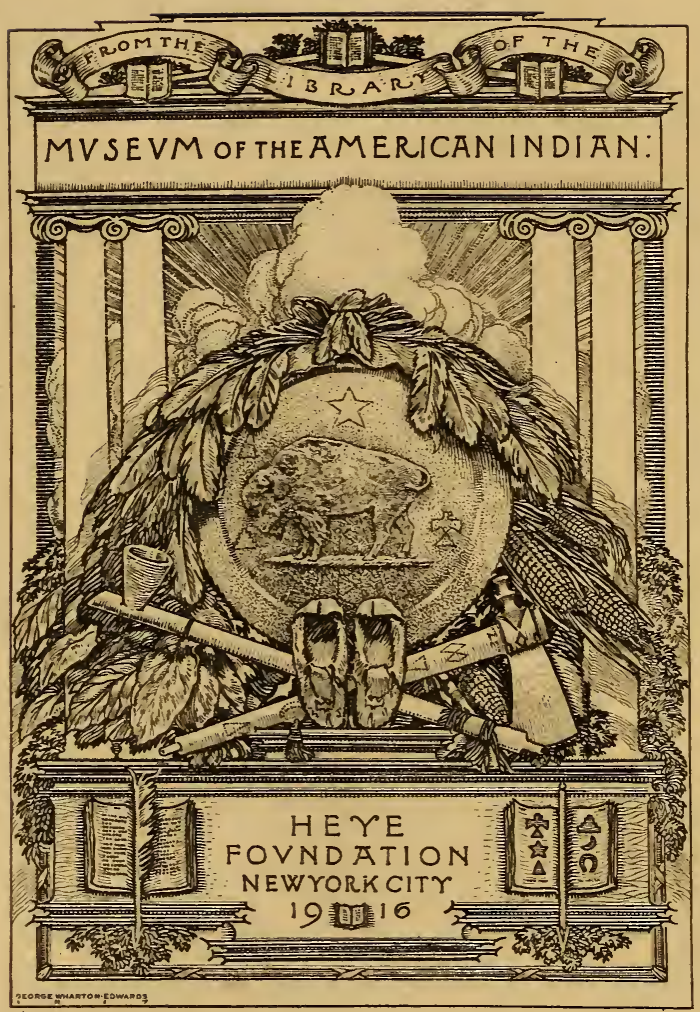






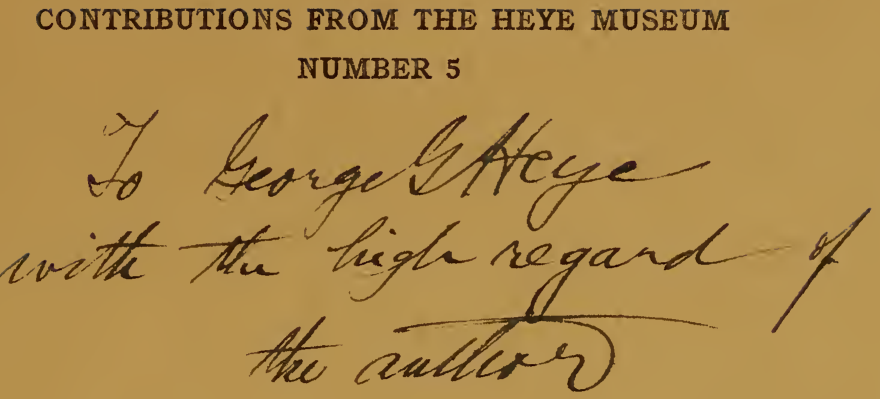

NOTE ON THE ARCHEOLOGY OF CHIRIQUI

By GEORGE GRANT MACCURDY

Reprinted from the American Anthropologist (n.S.), Vol. XV, No. 4, October-Decernber, I9I3

Lancaster Pa., U. S. A. The New Era Printing Company $\mathrm{rg} 4$

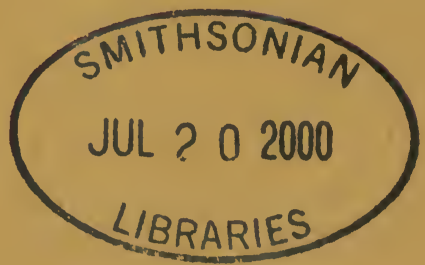



[Reprinted from the American Anthropologist, Vol. 15, No. 4, Oct-Dec., 1913.]

\section{NOTE ON THE ARCHEOLOGY OF CHIRIQUI}

\section{By GEORGE GRANT MACCURDY}

$\mathrm{T}$

HE faunal environment of a given region is apt to be reflected in its primitive art, especially when the art is primarily of local origin. The province of Chiriqui, Republic of Panamá, affords a good example of this interrelation. Archeologically the most common medium of art expression is pottery. The principal motives in the ceramic art of Chiriqui have been traced to certain animal forms. For example, the armadillo and motives derived from that animal, or parts thereof, are so dominant in one large class of pottery as to justify the name armadillo ware for that par-

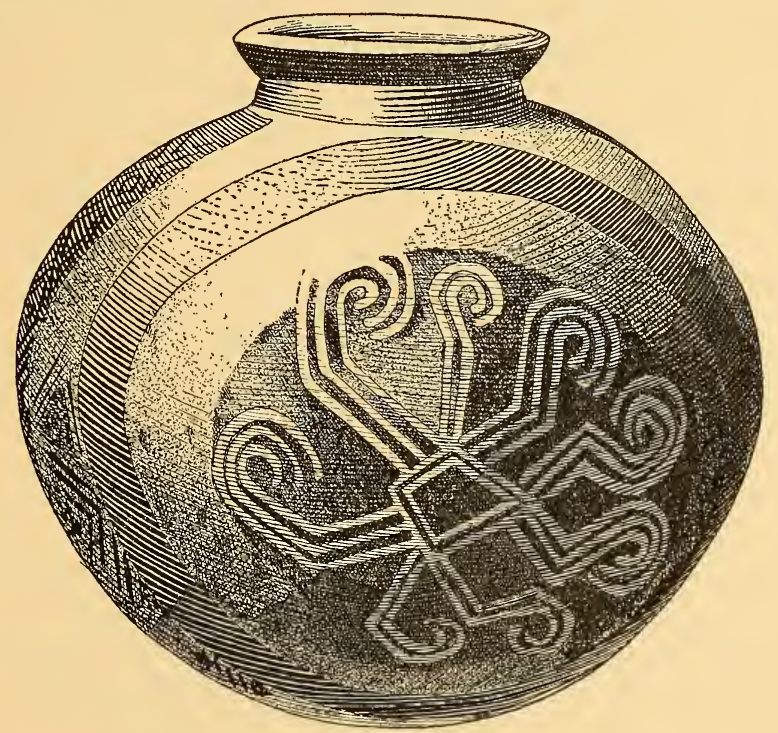

FIG. I49.-The octopus design as a panel decoration. Lost color ware. Heye collection, cat. $\frac{3}{3} 5^{3} \mathrm{I}$. $\quad(3 / 4)$

ticular ceramic group. For a like reason other groups are appropriately called serpent ware, fish ware, and alligator ware. Very few motives can be traced to plant originals. 
Recently Professor Marshall H. Saville of Columbia University called my attention to the decoration of an ancient vase collected by Mr George G. Heye while in Chiriqui during the month of January, 1913. The vase (fig. I49), which is in a perfect state of preservation, belongs to the so-called lost-color ware. The chief ornamental feature is enclosed in a large circular panel on the side of the vase and repeated on the opposite side. It consists of a diamond-shaped body and eight extremities somewhat evenly distributed, and all curved at the distal end as if to suggest a prehensile or clinging character. In drawing some of these appendages the artist apparently misjudged the space at his disposal or else purposely made some of the appendages smaller than others. All are composed of similar elements. The five larger, however, are made up of three parallel bands; while in each of the other three space enough was left for only two parallel bands. The original was evidently an animal form without apparent head or tail or even antennæ, but with exactly eight appendages that are also relatively large in comparison with the size of the body. Moreover, alternating with the two circular panels are two rather narrow vertical panels, in which motives (similar to fig. 150) are repeated that are derived from the same animal form. When showing me this vase Professor Saville suggested, and it seems to me with reason, that the octopus is here represented. It might also represent a cuttlefish of the octopod type. Both are known to exist in Isthmian waters and by their nature would be calculated to leave an indelible impression on the primitive mind.

Had Mr Heye's splendid specimen been a part of the United States National Museum collection when Holmes wrote his Ancient Art of the Province of Chiriqui, ${ }^{1}$ or of the Yale collection when I was preparing A Study of Chiriquian Antiquities, ${ }^{2}$ it would have suggested to him or to me the meaning of certain puzzling motives encountered at the time-puzzling because of the absence of the realistic stages in their evolution. For example, figure I50 (Holmes' fig. 27I) was considered by him to be a "highly conventionalized

${ }_{1}$ Sixth Ann. Rep. Bur. American Ethnology, Washington, I 888.

2 Memoirs Conn. Acad. Arts and Sciences, vol. IIr, Yale University Press, I9r. 
alligator derivative." That it is, however, derived from the same original as the design on the Heye vase is now quite apparent. The

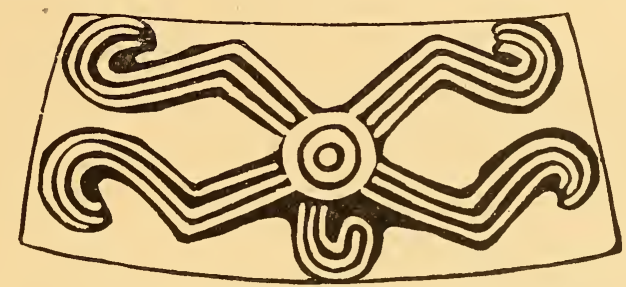

FIG. 150.-The octopus motive. (After Holmes.)

same is true of figure I5I (Holmes' fig. 275), a very interesting example of the use of the octopus appendages to form a pleasing running ornament independently of the body of the animal. Figure 152

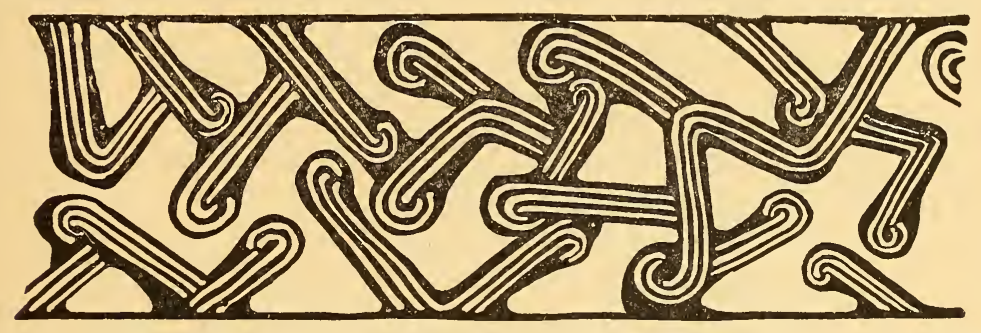

FIG. I5I.-The octopus appendage repeated to form a decorative motive. (After Holmes.)

(Holmes' fig. 238), a detail from a drum-shaped vase of the lostcolor ware, is a variation of the same thing.

In the light of the foregoing, geometric designs like that in figure

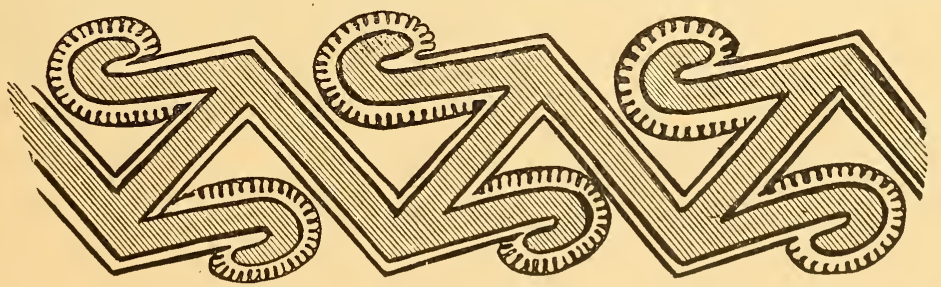

Fig. I52.-Conventional design on drum. (After Holmes.)

I53, from the shoulder of a bottle-shaped lost-color vase (Holmes' fig. 272), take on a new meaning. The rosette-like designs filling circular panels on numerous small lost-color vases figured by both 
Holmes and myself, are likewise probably traceable to an octopuscuttlefish original. An example from my own work (fig. 194) is reproduced in figure $\mathbf{1 5 4}$. The row of spots following the convexity

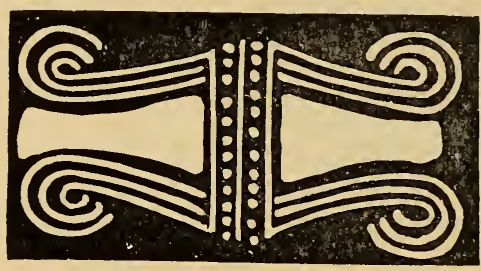

FIG. I53.-Octopus derivative. (After Holmes.) of the four curving arms are properly placed to represent the suckers of the octopus appendage.

The vase reproduced in figure I55 (pl. XLII, fig. $a$, of my monograph) is worthy of a detailed description. All the original ground is red with the exception of the peripheral band and those tangent to the neck, which are white. They were painted on first; then the bottom and the upper panels were colored red; finally came the waxing process and the coat of black, which was eventually removed from the design by melting the wax. This specimen is from Divala, and is not only beautifully modeled and painted, but also one of the best preserved of the entire group. The outline is softly angular, due to the sloping shoulders and slightly pointed bottom. The equatorial band cuts the body into two almost identical halves, the upper being surmounted by a narrow neck and projecting but wellformed lip. The framework of bands is a thick white paste that has received a high polish. The red field encroaches somewhat on the margins of the bands, and the black, the last to be applied, narrows them still more. The lower half of the vessel is in two zones, collection. (2/3) the nether of red and the upper of

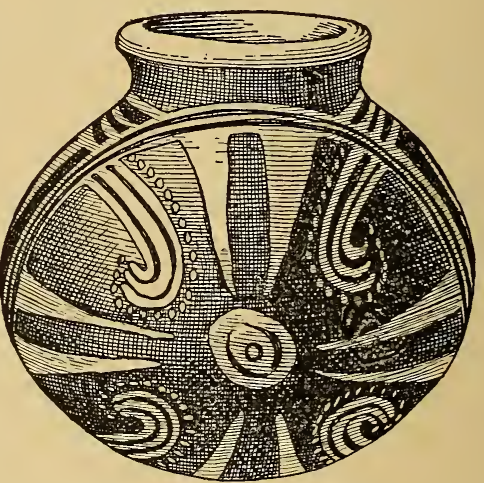

FIG. I54.- Lost color vase with octopus motive as a panel decoration, Yale black, with groups of narrow longitudinal bands. The neck and lip are also banded. Of the four panels surrounding the neck, the vertical ones are decorated with triangles.

The design in the arched panels, alike on both sides, I said at 
the time (page II2) "May or may not be construed as a life form. The diamond-shaped center may represent the body, and the six appendages, the head, tail, and legs. These are all composed of the same elements-a short straight band accompanied by two longer curving parallel bands. The four short appendages are attached to the center of the four sides of the square; the two long ones, at opposite corners. The whole is a piece of decorative work admir-

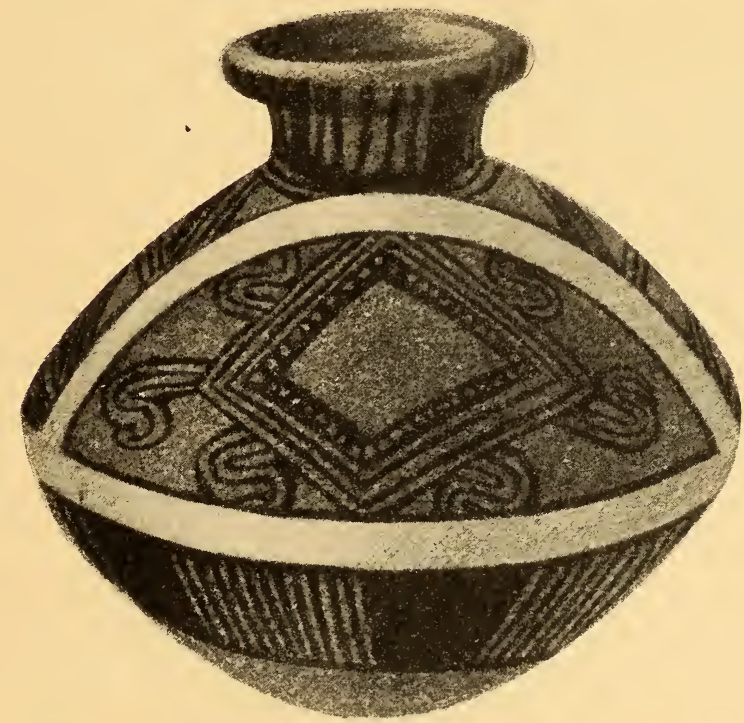

FIG. I55. - Beautifully modeled lost color vase with octopus design as a panel ornament. Yale collection. $\left(\frac{3}{5}\right)$

ably conceived and adapted to the space at the artist's disposal. The design may have no significance other than this." It now appears that this is also the octopus design with exaggerated body and appendages, relatively small and reduced in number.

Figure 156 is another example from my volume already cited (fig. 199). A frondlike motive, apparently derived from the octopus appendage, is repeated over and over again. A median point on the bottom is the center. Through it pass four slender vertical parallel bands reaching from a position half-way between the handles on one side to a like position on the opposite side. Beginning at the 
bottom and ascending on each side to the neck are successive pairs of opposite fronds. Each frond consists of three slender parallel bands rather sharply curved at the tips, with a single row of spots adjacent and parallel to the longer upper band; these follow the convex margin of each appendage as they do in figure I54. In some cases this row of dots is carried up the stem to the base of the suc-

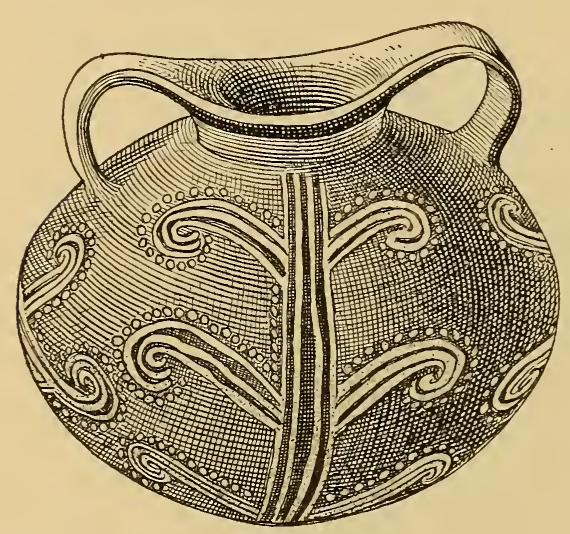

FIG. 156.-Lost color vase ornamented with octopus motives. Yale collection. (1/2) ceeding frond. In the large field below the base of each handle there is a design with a diamond-shaped center and six frondlike appendages, recalling the design in the arched panels of the vase reproduced in figure 155 .

Still further removed from the octopus original is the design on the vase reproduced in figure 157 (fig. 181 of my work previously cited). This vase had seen much service, the recurved lip having disappeared piecemeal. The broken surfaces are aged and smoked, and the tone of the entire red ground is deepened. On opposite sides of the body are life forms in low relief. Alternating with these are two four-sided panels, each filled by a painted design that I once said "retains only slight traces of a life form." It now appears to me like eight (the correct number) octopus appendages so disposed as to form a pleasing decorative motive. On the opposite side the combination of these same elements is such as to produce an equally original though somewhat different design.

It is worthy of notice that designs derived from the octopus are confined to one great group of Chiriquian pottery-the socalled lost-color ware. This is in keeping with what was found to be the case with other animal motives. The armadillo dominated one group, the serpent another, the fish a third, and the alligator two closely related groups. Again, a given technique prevails in 
each group. In the armadillo and the fish ware the designs are in the round or in relief; in the serpent ware the motives are incised and incisions filled with a white substance; in the alligator and the polychrome ware, the alligator motives are in color; and this we now find to be likewise true of octopus motives.

I realize that decorative and symbolic art is not to be demonstrated by mathematical formulæ. That its manifestations are, however, subject to laws of growth, and one might add decay, there can be little doubt. In the evolution of art the haphazard plays an insignificant rôle. The reasons for each step may not always be obvious, but they exist nevertheless. The work of a given

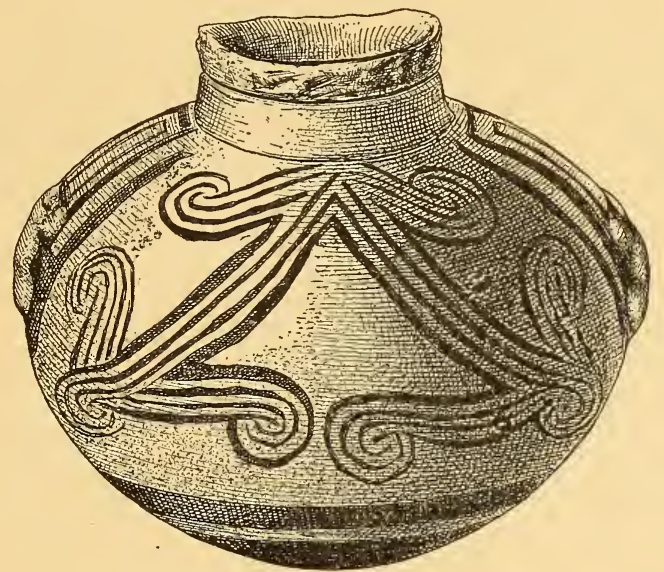

FIG. 157.-The octopus appendage repeated eight times to form an ornamental pattern. Lost color ware. Yale collection. $\left(\frac{3}{5}\right)$

artist reflects alike his spiritual makeup and his environment, cultural as well as natural. Without insisting that the model for the design in figure 149 is an octopus, one is certainly justified in affirming a genetic relationship between that design and those in the subsequent figures (especially I50, I54, I55, I56, and I57). Their kinship therefore has a more solid basis than mere fortuitous convergence toward a common type. Each artist either had in mind the common source of inspiration or else copied from some one who was drawing from that original source.

YALE UNIVERSITY

New Haven, ICONneCticut 







